\title{
Flow instabilities in a horizontal thermosyphon reboiler loop
}

\author{
EO Agunlejika, PA Langston, BJ Azzopardi, BN Hewakandamby \\ Manufacturing and Process Technologies Research Division, Faculty of Engineering, \\ University of Nottingham, Nottingham NG7 2RD, United Kingdom
}

\begin{abstract}
Thermosyphon systems have been the subject of several studies due to instability issues negating their attractive high heat fluxes, low temperature gradients requirement, reduced weight and simple, pump-less system. There is a dearth of design data for horizontal thermosyphons hence the transient behaviour of a horizontal thermosyphon reboiler loop has been studied experimentally here. Most studies here have explored and defined geysering instability in single and parallel vertical columns with closed bottom end. This study presents geysering detected in $51 \mathrm{~mm}$ riser of a horizontal thermosyphon reboiler.

Experiments were undertaken with water as the process fluid and steam as the heating medium, using $6-20 \mathrm{~kW} / \mathrm{m}^{2}$ heat flux, $1.165-1.265 \mathrm{~m}$ static head and a range of recycle flow restrictions. Pressure, temperature and flow rate data were continuously logged at $100 \mathrm{~Hz}$. Flow rate was examined as a significant indicator of instability since it is the parameter with highest and varied amplitude of oscillation. Heat flux is most significant for stability: above $20 \mathrm{~kW} / \mathrm{m}^{2}$, the system is stable; between $11-20 \mathrm{~kW} / \mathrm{m}^{2}$ there are varying degrees of sustained oscillations and below $11 \mathrm{~kW} / \mathrm{m}^{2}$ flow rate is low. Reboiler inlet flow restriction also stabilises the system by reducing the flow rate to such a level that heat transfer rate can maintain a consistent vapour product rate. Static head influences the recirculation rate and subcooling at the reboiler inlet, but has a secondary effect on stability. Churn flow pattern is detected in the riser as a characteristic aftereffect of the cyclic instability.
\end{abstract}

Keywords: Thermosyphon, Horizontal reboiler, Thermo-hydraulic instability, Geysering, two-phase heat transfer 


\section{Introduction}

Two-phase flow instabilities were first reported by Ledinegg (1938) while investigating two-phase flow in steam generators. These flow instabilities are encountered in all sizes of hydraulic diameter. Flow instabilities are undesirable particularly in boiling, condensing, and other two-phase flow processes. This is because heat input and removal in two-phase flow induces a large volumetric change owing to phase changes so the system easily becomes unstable. These unstable flows are sustained since conditions leading to instability in the system are hydrodynamic in nature and interlinked through feedbacks between flow rate, pressure drop and heat transfer. Sustained flow oscillations may cause forced mechanical vibration of components or system control problems. Also flow oscillations affect the local heat transfer characteristics and may induce a boiling crisis (critical heat flux (CHF), burn-out, dry-out) (Boure et al., 1973). These undesired effects can degrade the heat transfer performance. One way of reducing the problems of instability is to introduce a restriction or gag at the entrance, provided of course that the pressure drop penalty is acceptable (Hewitt et al., 1994). Several review articles have been written to present the phenomena and theories involved (Boure et al., 1973), (Ishii, 1976), (Bergles, 1976), (Yadigaroglu, 1981), (Rouhani and Sohal, 1983), (Dhir, 1998), (Cheng and Mewes, 2006), (Durga Prasad et al., 2007), (Kakac and Bon, 2008), (Saisorn and Wongwises, 2008).

Reboilers that operate two-phase flow may be susceptible to several kinds of instability depending on the geometry and system characteristics. Process conditions, heat input distribution, driving force for circulation, hydraulic resistance of various parts of the system, and properties of the working fluid are also variables (Chexal and Bergles, 1972). Most of the instabilities mentioned by Boure et al. (1973) concerned forced circulation systems. But natural circulation modes are considered to be more susceptible to instabilities since their flow is induced by the difference in fluid density and sustained by the feedbacks of pressure drops, and heat transfer.

Thermosyphons are characterized by high heat transfer rates and low fouling tendencies. They can be operated over a range of pressures and have proven adequate for heavy heat duties in petroleum industry. Horizontal thermosyphon reboilers exhibit complex interaction between two-phase flow, 
heat transfer, and circulation through the temperature-influenced, density-gradient initiated flow. But flow instabilities with periods of a minute or more are known to have caused problems in commercial horizontal thermosyphons. They appear not to have been studied in the literature, although a number of studies of the analogous 'density wave instability' in vertical thermosyphons have been published (Alane and Heggs, 2011). Unstable operation of a horizontal thermosyphon reboiler were reported by Hills et al. (1997) but they did not record surface temperature in the reboiler and hence could not calculate shell-side heat transfer coefficient. Likewise, they did not measure the pressure at the base of the sump and so could not estimate the single phase pressure drop of the return liquid. However, they identified low heat flux, low inlet resistance, low driving head and high inlet sub-cooling as conditions encouraging instability. Durga Prasad et al. (2007) highlighted system pressure, mass flow rate, inlet resistance, inlet subcooling and increasing riser length as influencing factors in general in natural circulation boiling systems. Azzopardi and De Leon (2008) reports that the unstable region is characterised by fluctuations in the inlet temperature to some tubes, an increase in the shell-side pressure and temperature, and a decrease in the circulation rate and overall heat transfer coefficient. But they also operated at high fluxes.

The specific type of instability most common in thermosyphons is flow-focused, oscillatory in nature, cyclic due to pressure drop feedback and occurs at low heat fluxes; geysering is a particular example. According to Duffey and Rohatgi (1996) the onset of geysering is the point where large increase in pressure drop accompanying nucleate and bulk boiling causes substantial flow reduction or excursion. Griffith (1962) was acclaimed to be the first to study geysering. He used methanol and water in closed end tubes with different lengths and diameters without circulation and reported suppression of geysering by limiting free volume in the vessel and period of order 10-100s. Kuncoro et al. (1995) described the geysering cycle as periods of boiling, expulsion and refilling as shown in Figure 1. 


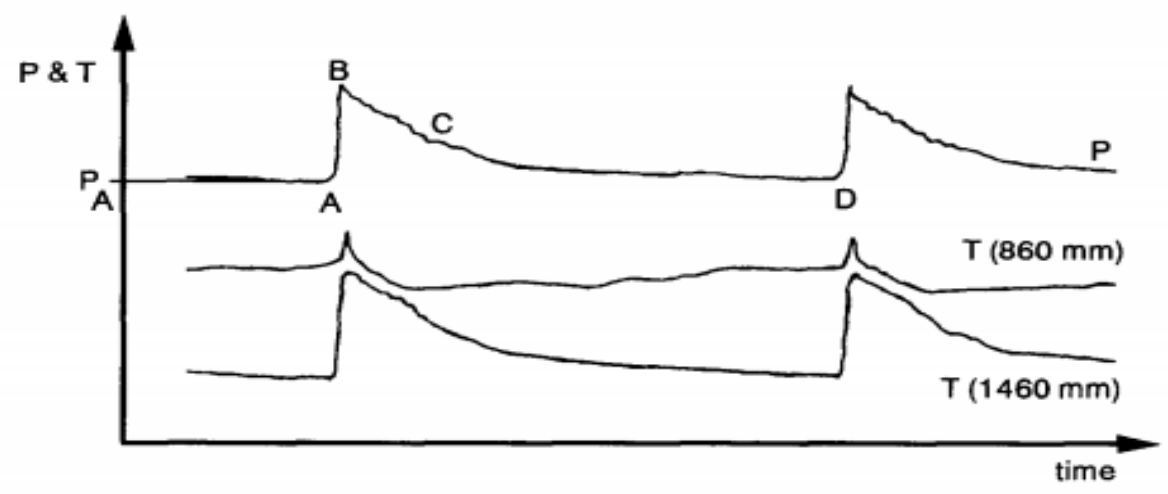
A - B : Expulsion process
B - C : Boiling process
$P_{A}-P_{B}$ : Pressure amplitude
C - D : Quiet condition (waiting time)
$T_{A}-T_{B}:$ Temperature amplitude
A - D : Geysering period
$P_{A}$ : Set pressure

Figure 1: Geysering cycle by Kuncoro et al. (1995)

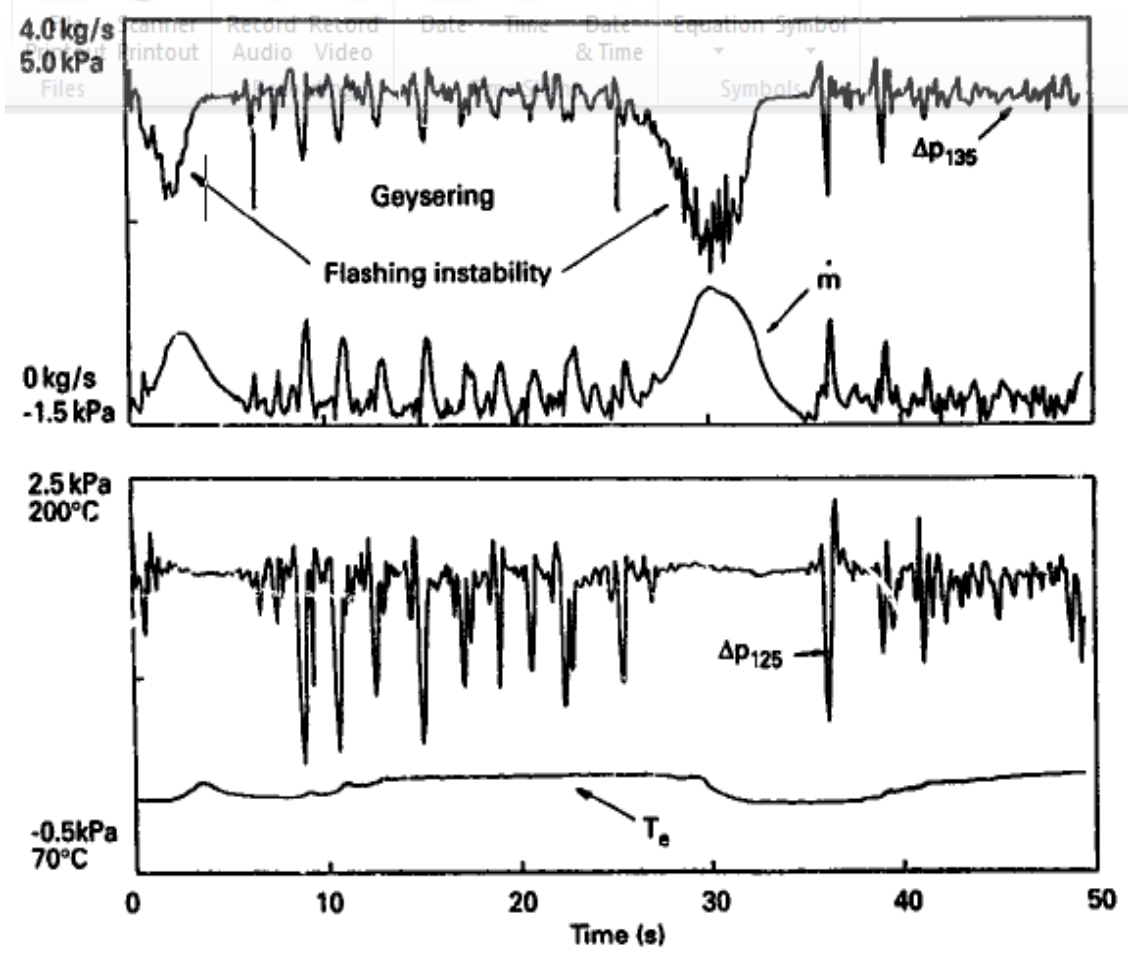

Figure 2: Geysering instability with flashing observed by Jiang et al. (1995)

The period is estimated by adding the times of the individual segments of the cycle. Geysering has so far been observed in vertical liquid column with a closed end and heated near the bottom, and parallel channels (Ozawa et al., 1979), (Masuhara et al., 1993), (Aritomi et al., 1993), (Kuncoro et al., 1995), (Rao et al., 1997), (Kim and Lee, 2000), (Khazaee et al., 2010). Jiang et al. (2000) reported that geysering instability detected is a function of the geometry, configurations and working fluid. Their observation show flashing accompanying geysering in Figure 2. This paper follow the works of Hills et al. (1997) and Azzopardi and De Leon (2008) which appear to be the 
only precursor published papers on instabilities in a horizontal thermosyphon reboiler. This study is aimed at presenting experimental data from investigating the instability using a set of lowest possible heat fluxes, static liquid head and reboiler inlet flow restriction. The mechanism of geysering identified in such a system is also presented.

\section{Experimental arrangement}

In order to study the operational behaviour of the horizontal tube thermosyphon reboiler loop, a steam-heated vapour-water facility was designed. This is schematically depicted in Figure 3 . It is a loop facility that is useful in phenomena tracking. The rig is limited to about 2 bar gauge pressure of steam. The facility consists of a reboiler, riser, condenser, sump and recirculation pipe. The riser is a $0.051 \mathrm{~m}$ OD pipe, $1.61 \mathrm{~m}$ vertical height with two $45^{\circ}$ and one $90^{\circ}$ bends installed at 21 and 32 pipe diameters downstream of the reboiler which notably contribute to pressure drop in the riser. A fixed liquid level is achieved in the sump by the use of overflow weir which also keeps the reboiler tubes fully submerged. The $0.305 \mathrm{~m}$ OD reboiler is steam-heated through 16 tubes $(10$ are $0.752 \mathrm{~m}$ long, pitch $0.025 \mathrm{~m}$ and 6 are $0.902 \mathrm{~m}$ long, pitch $0.035 \mathrm{~m} ; 0.15 \mathrm{~m} \mathrm{OD)} \mathrm{shown} \mathrm{in} \mathrm{Figure} 4$ while the process fluid flows in the shell-side. Heat transfer area is $0.6094 \mathrm{~m}^{2}$. It replicates the TEMA G-type shell-and-tube heat exchanger with a $0.3 \mathrm{~m}$ wide and $0.2 \mathrm{~m}$ long central horizontal baffle to prevent liquid channelling and a central vertical tube plate. For safety reasons, water rather than another chemical is employed as the process fluid. The reboiler and the riser constitute the most important units because the development of the temperature difference and hence the density gradient in them influence the balance of forces which initiate the flow around the whole loop while the sump replicates the characteristics typical of bottom section of a distillation column. Average process temperature at the reboiler entrance is $102.6^{\circ} \mathrm{C}$ with water as process fluid. The riser and the sump are made of borosilicate glass (possibly from QVF) which enables visual observation and use of high speed camera.

The temperature distributions around the system are measured using T-type Ni-Cr thermocouples. The pressures, including the process pressure (absolute), are measured using pressure transducers 
located at identified positions around the rig as shown in Figure 4. The recirculation rate is metered using an electromagnetic flow meter with a maximum flow rate of $1.8 \mathrm{kgs}^{-1}$ installed on the recirculation pipe 15 pipe diameters upstream of the reboiler. The uncertainty of the measurements was approximately $\pm 1^{\circ} \mathrm{C}$ for temperatures, $\pm 2 \%$ for pressures and $\pm 4 \%$ for flow rate. Measurements of the process condensate and steam condensate flows are made by separate collection in graduated borosilicate glass vessels, both over timed periods.

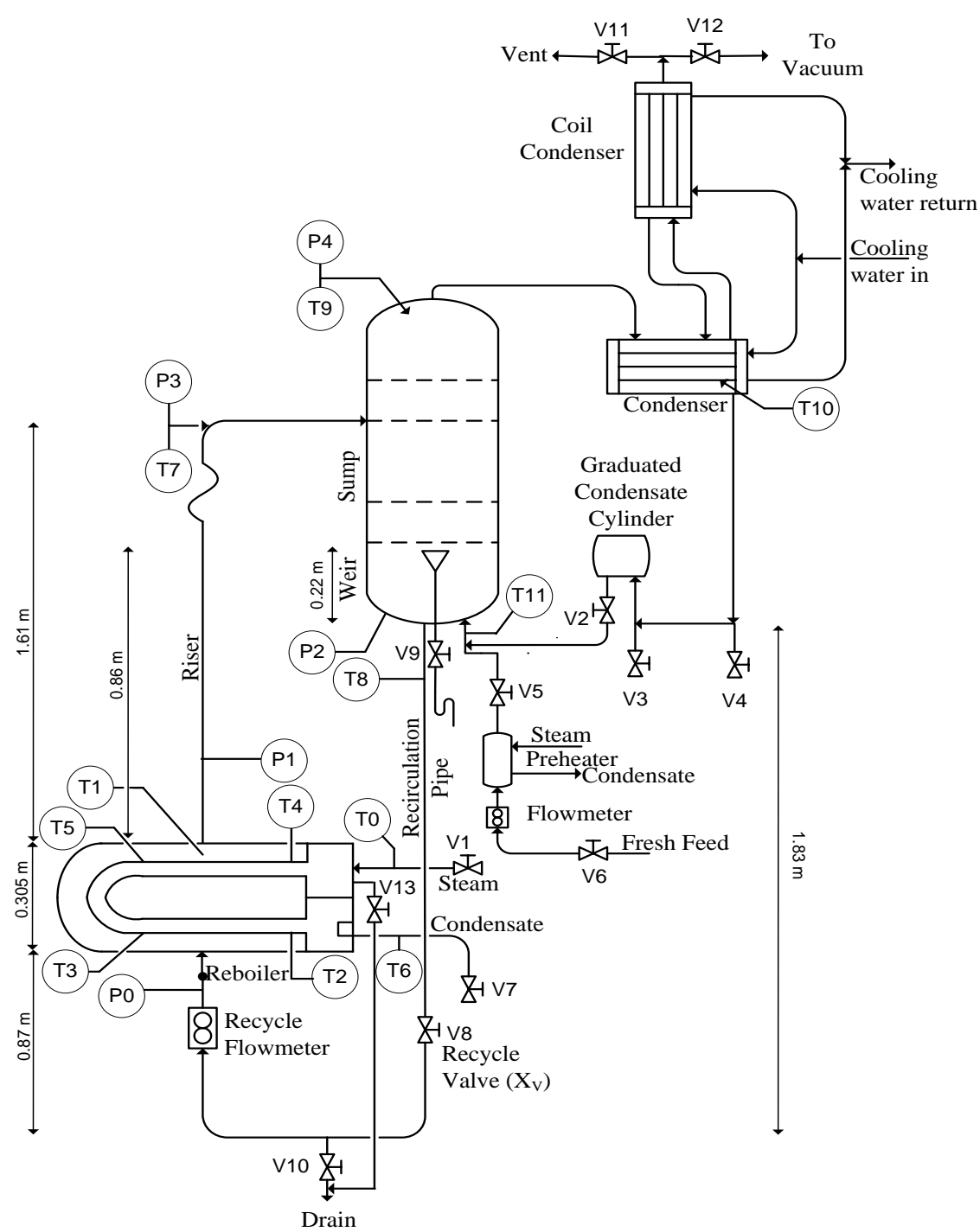

Figure 3: Schematic drawing of the test facility. 


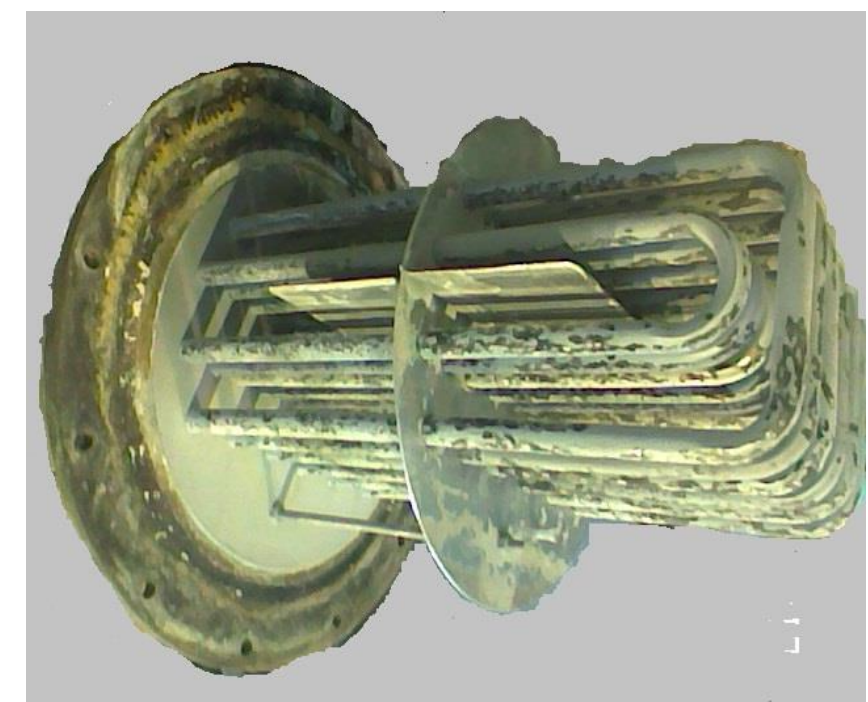

Figure 4: The reboiler displaying the 16 U-tubes

The variables of interest are the steam pressure for the heat flux, recycle valve setting for the reboiler inlet flow restriction, and the overflow weir height for the static liquid head. Steady state pressure, temperature and flow rate data are logged for a period of $200 \mathrm{~s}$ at frequency of $100 \mathrm{~Hz}$. The effects of heat flux, static head and flow restriction on flow rate, vapour production rate and system stability are investigated; the main parameters are presented in Table 1 below.

Table 1. Parameters for experimental runs

\begin{tabular}{llc}
\hline \multicolumn{1}{c}{ Parameter } & \multicolumn{1}{c}{ Value (Unit) } & Symbol \\
\hline Utility steam pressure & $1.28,1.34,1.41,1.48,1.62 \mathrm{bar}(\mathrm{a})$ & $\mathrm{P}_{\mathrm{S}}$ \\
Equivalent heat flux & $6,9,11,14,20 \mathrm{~kW} / \mathrm{m}^{2}$ & $\mathrm{q}$ \\
Equivalent saturated & $106.7,108.0,109.5,110.9,113.7^{\circ} \mathrm{C}$ & $\mathrm{T}_{\mathrm{sat}}$ \\
temperature & $0.091,0.136,0.182,0.25,0.5,0.75,1$ & \\
Valve position & $(0=$ fully shut, $1=$ fully open $)$ & $\mathrm{X}_{\mathrm{V}}$ \\
Weir height & $1.165-1.265 \mathrm{~m}$ & $\mathrm{~h}_{\mathrm{W}}$ \\
\hline
\end{tabular}

\section{Experimental results}

The feedback relationship between the heat input, pressure drop and recirculation rate characterizes the performance of a reboiler system. Hence, the stability of the system is studied through varying heat input (steam pressure), recycle valve setting (V8, inlet resistance) and static liquid head (overflow weir height). It is observed in most cases that only recirculation rate displays 
substantial oscillation which can be quantified. It could be therefore inferred that flow rate is a significant indicator of stability in such a system as is further discussed in the following sections. In the discussion symbols in Table 1 are used for simplicity. A generic pressure profile is shown in Figure 5 devised from measurements on the facility as in Figure 4.

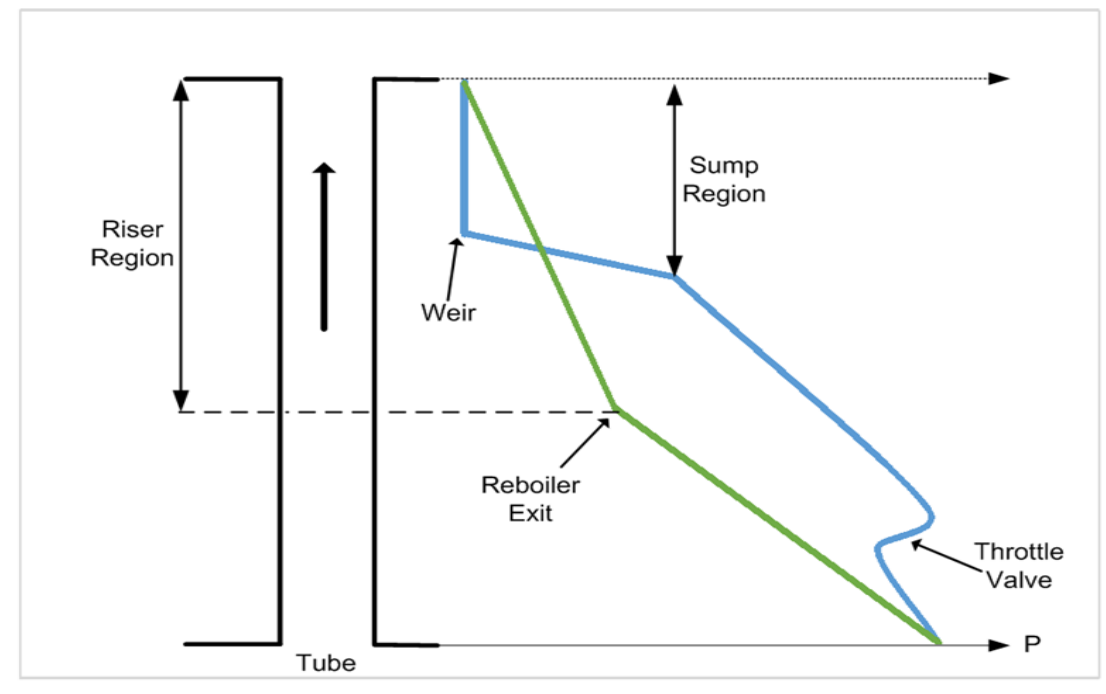

Figure 5: Pressure profile of the research facility

\section{Heat transfer}

Heat transfer characteristics of the system are evaluated from equation (1). The total heat transfer rate is computed as

$$
\dot{Q}=\dot{m}\left\{C_{P G} \delta T_{\text {super }}+\lambda+C_{P L} \delta T_{\text {sub }}\right\}=U A \Delta T
$$

Since logarithmic mean temperature difference is not valid for non-linear temperature profiles here, $\mathrm{U}$ is estimated using average of

$$
\begin{aligned}
& \Delta T=T_{1}-T_{8} \\
& \Delta T=T_{0}-T_{6}
\end{aligned}
$$

for shell side and tube side approximations respectively. The heat supplied by the steam is partly lost while the rest heats up the shell-side process fluid. The heat losses are estimated to be about $25 \%$ of the total. Recirculation flow rate as a function of vapour production rate can be used to determine if the condition of the two-phase flow in the riser is gravity-dominated or friction-dominated. In Figure 6, the majority of the conditions covered appear to fall within the 
gravity-dominated flow regions characterised by low quality and velocity, and high liquid holdup. Azzopardi and De Leon (2008) reported values of heat transfer coefficient for same facility within the range 1.5-4.0 $\mathrm{kWm}^{-2} \mathrm{~K}^{-1}$. Comparison with Azzopardi and De Leon (2008) is presented in Figure 7. Note, the present study, though is carried out on the same facility, is at much lower heat fluxes and both results follow the same trend.

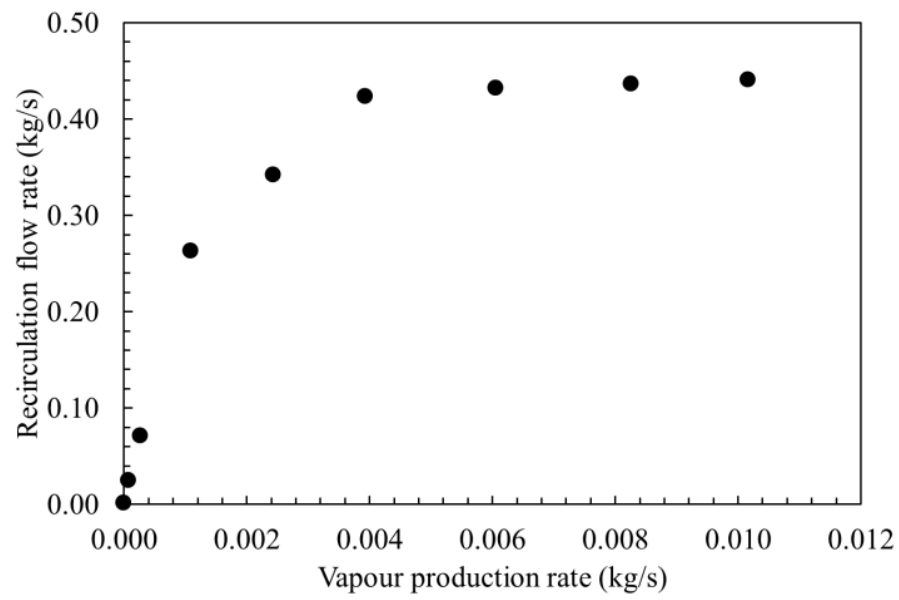

Figure 6: Recirculation flow rate at different vapour production rate

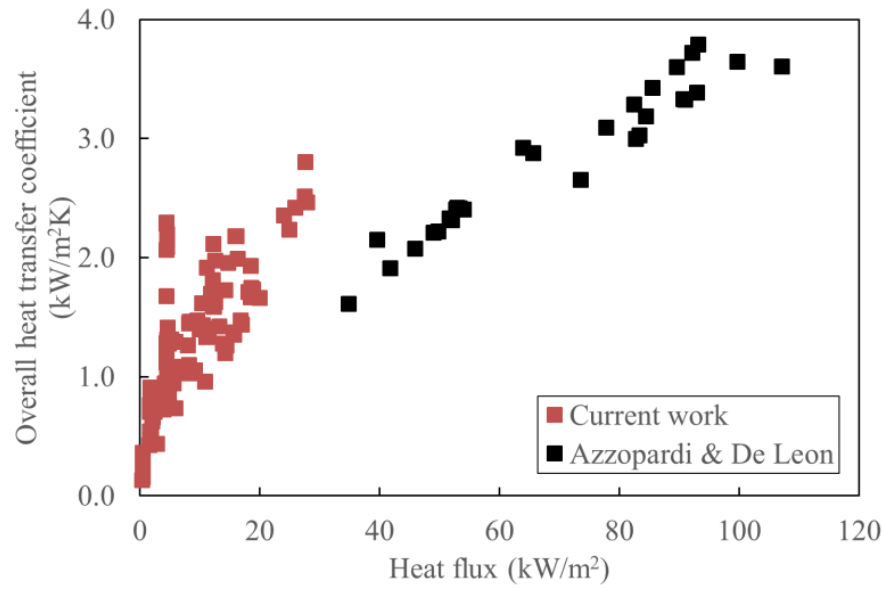

Figure 7: Dependence of overall heat transfer coefficient on heat flux

\section{Effects of heat flux}

The heat flux is a control variable necessary for understanding heat transfer in such a system. Influence of heat input is examined through variation of steam pressure as shown in Figures 8(a, b). The typical instability shown here was described by Azzopardi and De Leon (2008) as one of switching on and off. Chaotic oscillations of recirculation flow rate are identified as indication of instability in the system. These exhibit similar characteristics as flow-induced instabilities or geysering. Measured flow rates increase with heat flux. This increase is linked to increased vapour 
product rate. The system here could not attain recirculation at heat fluxes below $11 \mathrm{~kW} / \mathrm{m}^{2}$ because the heat losses in the boiler and riser are comparable with the rate of heat input.

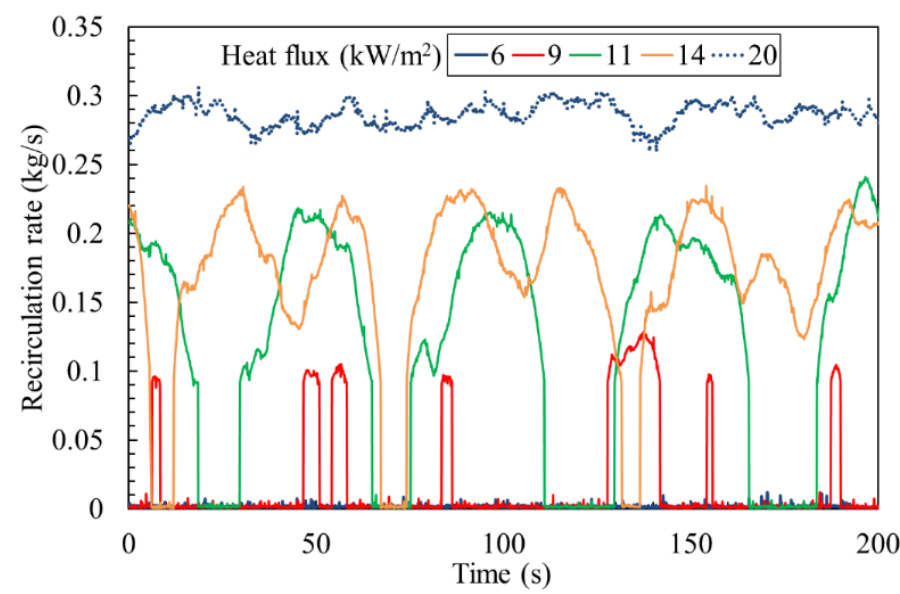

(a) $\mathrm{h}_{\mathrm{W}}=1.165 \mathrm{~m}, \mathrm{X}_{\mathrm{V}}=1.0$.

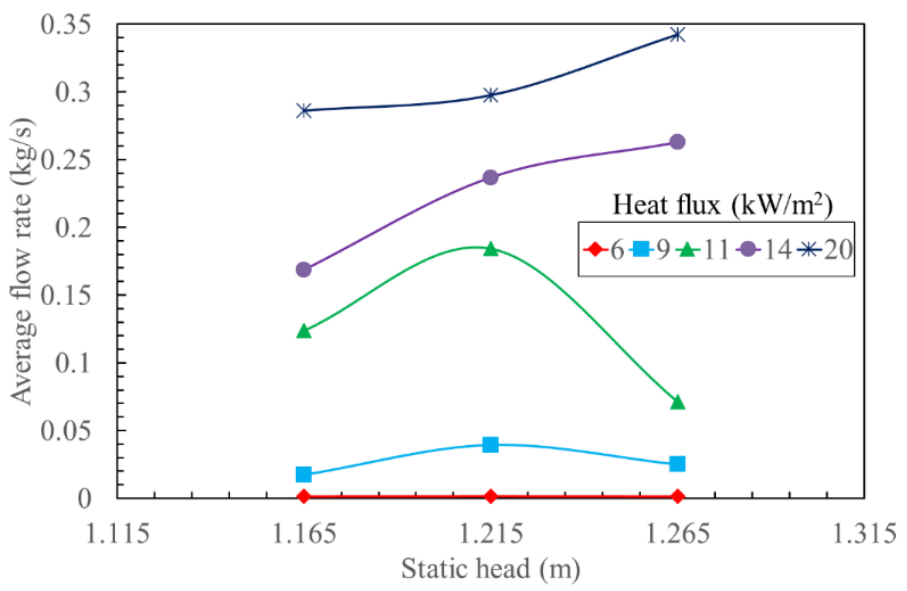

(b)

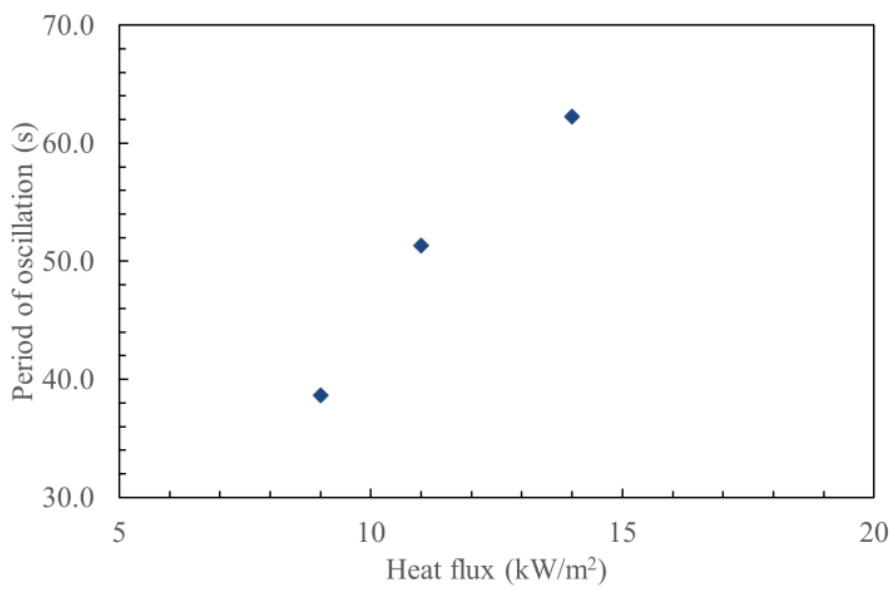

(c)

Figure 8: Influence of heat flux on flow rate

The exchanger inertia and hence the density difference are inadequate. It could also be due to the pressure drop factor not satisfied, i.e. the pressure drop at specified heat flux is inadequate to reproduce circulation. The minimum heat input under which this system is operable at atmospheric condition is $11 \mathrm{~kW} / \mathrm{m}^{2}$. Between $9-14 \mathrm{~kW} / \mathrm{m}^{2}$ intermittent oscillation characterizes the flow with increasing amplitude. It is noted that flow rate and its period of oscillation increases with heat flux until about $20 \mathrm{~kW} / \mathrm{m}^{2}$ as Figure $8(\mathrm{c})$ shows. Period of oscillation could not be estimated for 6 $\mathrm{kW} / \mathrm{m}^{2}$ because recirculation was not recorded while at $20 \mathrm{~kW} / \mathrm{m}^{2}$ the oscillation is marginal with inconsistent or momentary periods. So at about $20 \mathrm{~kW} / \mathrm{m}^{2}$ and above, the system displays stable flow and tends to stabilise with increasing heat input. 


\section{Effects of static liquid head}

Static head is an important parameter in the operation of thermosyphon reboiler because it can be manipulated to achieve a desired flow rate. The height of the funnel-shaped weir in the sump is used to vary the initial static liquid head available. It is observed that the liquid level in the sump rises about $0.05 \mathrm{~m}$ due to liquid influx being greater than outflow which results from high pressure drop at reboiler inlet. Flow is established by the difference between the static head and high liquid density in the sump and less dense two-phase mixture in the reboiler and riser. High static heads create high recirculation rates and can influence the margin of stability as shown in Figures 9. At low and high static heads $(1.165,1.265 \mathrm{~m})$, the flow is unstable while at moderate static head $(1.215 \mathrm{~m})$ the flow is stable with minor oscillations. So the amplitude of oscillation of flow rate rises with increasing static head. At moderate static head the fluctuation is mild so that decreasing liquid level in the sump promotes the instability

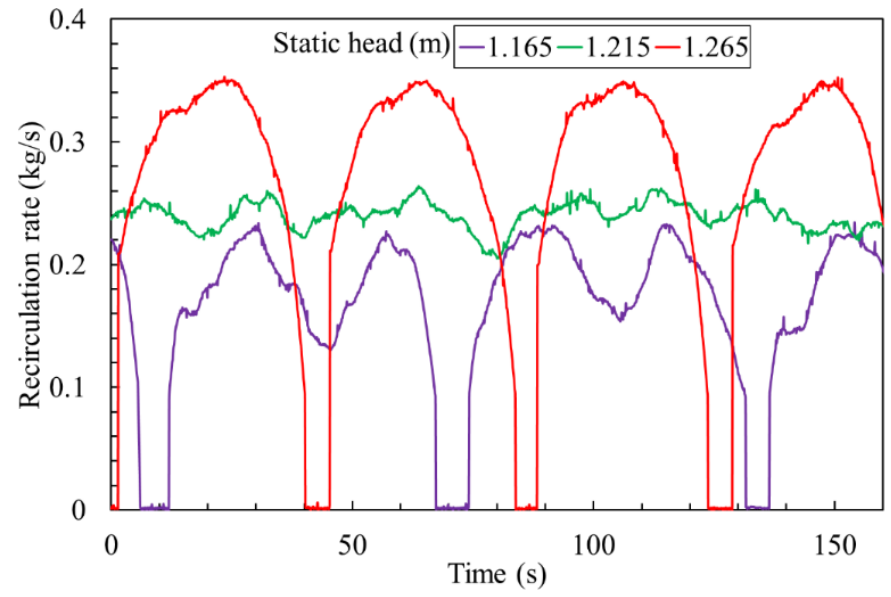

(a) $\mathrm{q}=14 \mathrm{~kW} / \mathrm{m}^{2}, X_{\mathrm{V}}=1.0$

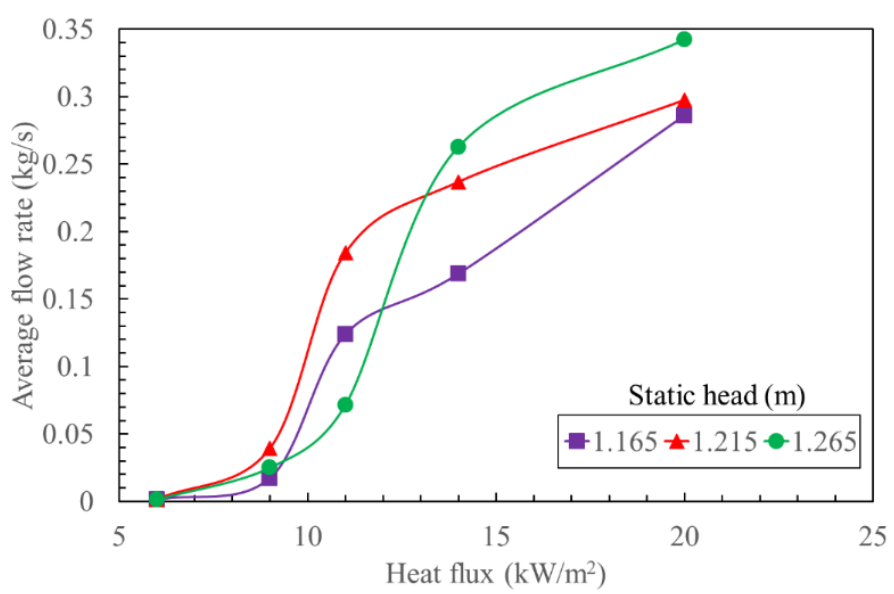

(b)

Figure 9: Influence static liquid head on flow rate

\section{Effects of inlet flow restriction}

There is a nonlinear relationship between the flow restriction and the flow rate. The major variations in flow rate occur between nearly shut valve $\left(X_{V}=0.091\right)$ and quarter open $\left(X_{V}=0.25\right)$. Figure 10 shows how recirculation flow rate increases with inlet flow restriction. This may partly explain why increasing inlet resistance stabilises the system. Flow restriction limits influx flow rate, allowing in less liquid per time at heat transfer rate. This reduces time needed to heat to 
saturation which enhances stability. Figure 11(a) illustrates that though the stop/go feature of the instability is prominent at all inlet resistance values, the amplitudes of flow oscillations decreases with inlet resistance. The period of oscillation sharply increases at high inlet resistance in Figure 11(b) and shows the influence of inlet resistance on the flow rate and stability of the system.

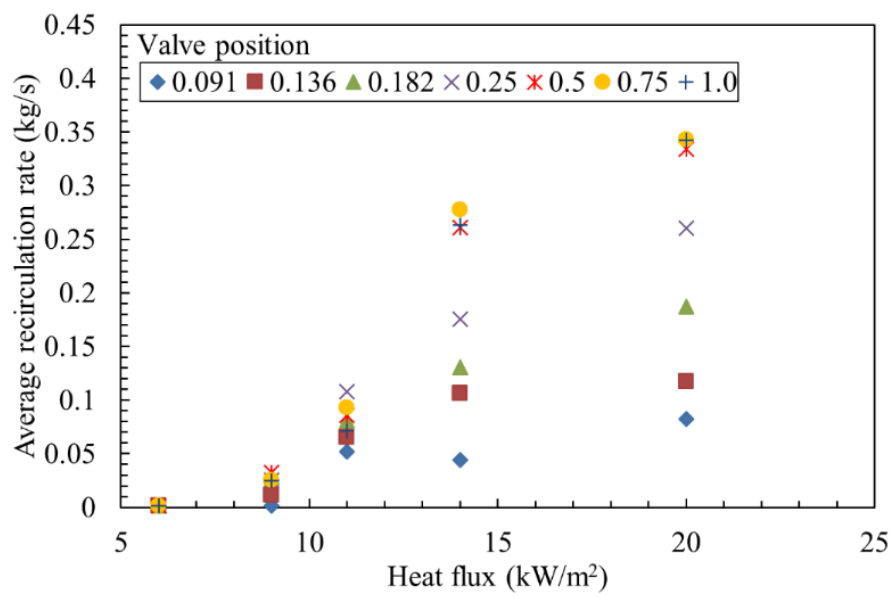

Figure 10: Effects of flow restriction on flow rate.

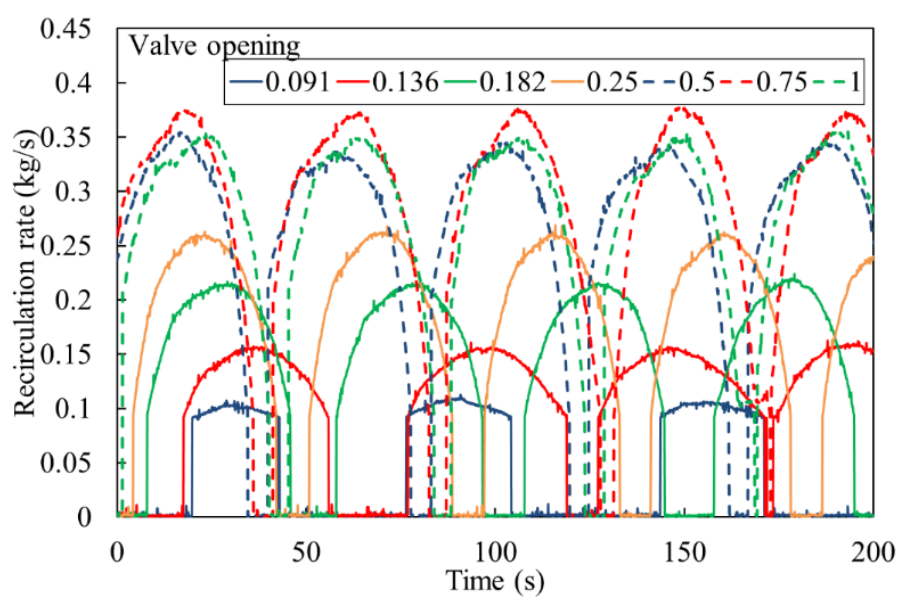

(a) $\mathrm{q}=14 \mathrm{~kW} / \mathrm{m}^{2}, \mathrm{~h}_{\mathrm{W}}=1.265 \mathrm{~m}$

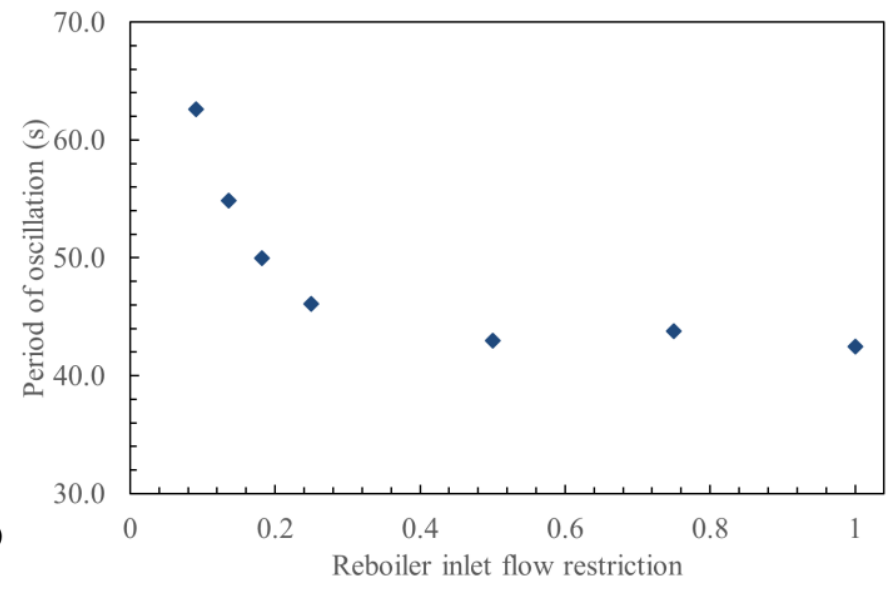

(b)

Figure 11: Dependence of flow rate on valve position

\section{Overview of instability}

The instability map, Figure 12, summarises the stability of the system from the experiments. There is a balance required between appropriate heat input and flow restriction at fixed static head to avoid instability. Observing flow rate conditions at different flow resistance and heat flux reveals unstable, neutrally stable (mild oscillations) and stable regions. It also helps to identify regions of operation where it is ineffective to operate the reboiler loop because the recirculation cannot be effected. The low flow occurs when heat losses and heat transfer rate are comparable. 


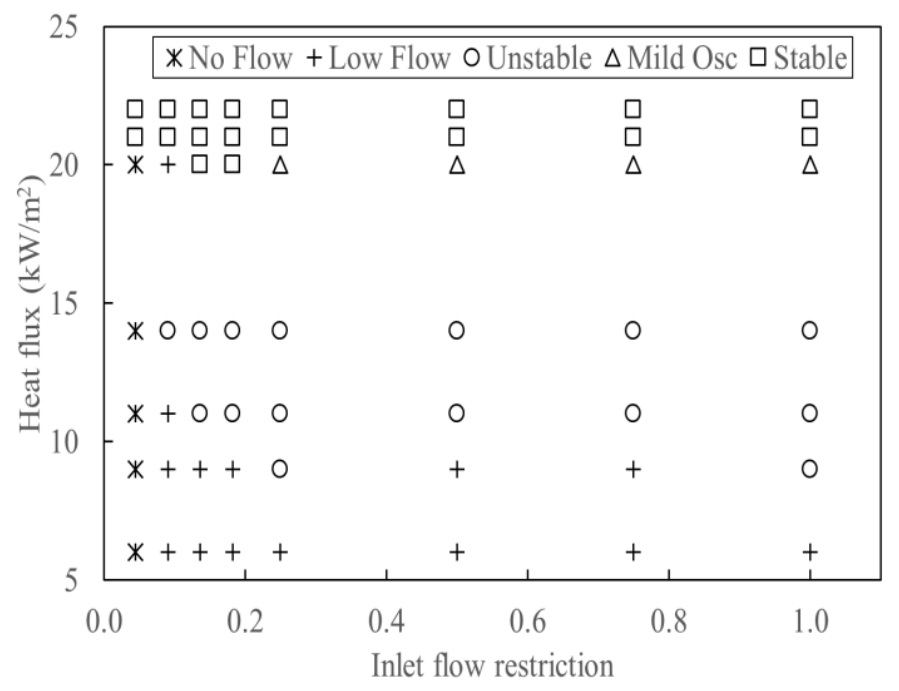

Figure 12: Stability map

\section{Unstable behaviour}

The instability detected is considered geysering. It is shown in the fluctuations of the flow rate, temperature and pressure in Figures 13(a-d). It is a violent boiling condition which occurs intermittently in a vertical riser with connection to a reboiler, a condenser and a sump with return pipe in a loop. It has been reported in tall risers downstream of heated sections, single and parallel channels, natural and forced circulation systems and at low heat fluxes and circulation rates. Geysering mechanism as explained by Griffith, P. (1962) supports observations reported in vertical heated sections without circulation while mechanism for systems with circulation was first proposed by Ozawa et al. (1979). Geysering as detected in the riser of a horizontal thermosyphon reboiler loop is an intermittent subcooled boiling condition initiated in the reboiler. It occurs when the liquid in the reboiler under hydrostatic pressure of the riser heats up to saturation and vaporisation starts. The reduction of the hydrostatic pressure drop in the riser due to presence of voids reduces the pressure in the reboiler leading to flashing and periodic expulsions of the boiling liquid and vapour mixture.

The process starts with heating of subcooled liquid in the reboiler and riser. Superheated zones exist in the riser because of insufficient nucleation sites. This is a quiet period of the process as flow rate and hence pressure drop are significantly low with no circulation. Boiling is initiated and exhibit bubbly flow pattern. There is a gradual transition from bubbly to slug flow pattern as the 
bubbles grow due to decreasing static head and coalescence. With increased vapour generation, the mixture gains inertia and effectively becomes churn flow. Hydrostatic pressure head at the top of the riser is lower. The density difference between fluids in the riser and reboiler, and liquid in the sump drives the normal flow but inertia due to the vapour produced promotes the violent expulsion of the vapour-liquid mixture into the sump. This leads to the development of churn flow at this stage. At the inlet of the sump, part of the liquid experiences flashing due to lower pressure. Pressure in the sump is approximately constant in spite of the liquid inflow from the riser. As the liquid level in the riser falls, vapour generation ceases with time decreasing vapour velocity which generates a large pressure wave. This initiates a large increase in circulation rates and consequently pressure drop to start subcooled liquid refilling stage. Once the reboiler and riser are refilled, boiling is quelled thus reducing the driving force. This consequently freezes the recirculation and increases enthalpy. The process then restarts.

During geysering pressure, temperature and flow rate display characteristic oscillations which may be specific to the fluid, configuration and systems. These oscillations represent the nature of the instability and can be used to study mechanism of the phenomenon. Pressure drop is determined from measured pressures. Oscillations typical of geysering in the system are illustrated in Figure 13(a). Pressure drop across the reboiler is relatively marginal compared to that in the riser and pipe. This may be due to the high hydrostatic head around the reboiler which limits the flow rate in the reboiler convective transfer. It appears pressure drop across the reboiler is mainly due to the subcooled boiling. However, it reveals a minimum when flow sets in which matches the onset of boiling and maximum after peak in flow which corresponds to termination of boiling. The maximum during boiling is due to large vapour bubbles lowering the void fraction which invariably decreases gravitational pressure drop. The pressure drop across the riser shows a minimum during the fall in flow rate and maximum at the onset of flow. The minimum corresponds to the single-phase flow when the velocity and vapour generation are low and thus gravity dominated. While the maximum represents the region of high velocity and quality corresponding to friction-dominated regime. Pressure drop across the recirculation pipe increases 
and decreases with flow rate and is at minimum when the flow terminates. This is because the gravity component is constant due to the pipe being full of liquid while the fractional component increases with flow rate.

Pressures across the reboiler (P0 and P1) show a consistent sinusoidal period of oscillations which is quite different to the instability feature shown by pressures in other parts of the system. It seems pressures $\mathrm{P} 0$ and $\mathrm{P} 1$ have adequately been isolated from other effects due to the high pressure produced from vapour generation and intermittent boiling in the reboiler. However, pressures P2 (hydrostatic in sump), P3 (two-phase in Riser) and P4 (process side) have amply illustrated the typical instability inherent in the system. This instability trend expressed is similar to the geysering cycle described by Kuncoro et al. (1995), Jiang et al. (2000) and Emami et al. (2009) with the expulsion stage being gradual. Geysering here is noted as resulting from the subcooled boiling condition. The quiet boiling, expulsion and refilling stages of the cycle are evident in P2, P3 and P4 of Figure 13(b). Hydrostatic pressure, P2, temporarily falls under partial vacuum during the dip part of the characteristic fluctuation. This coincides with cessation of flow when liquid level in sump is low and maximum pressure build-up in the reboiler. The sudden increase in vapour generation is due to the reduction in hydrostatic head. According to Duffey and Rohatgi (1996), it could also be due to equilibrium evaporation caused by heating, flow refilled by loop convection and condensation due to cooling in the riser.

Temperatures measured at various points within the reboiler are illustrated in Figure 13(c). T4 and $\mathrm{T} 5$ which are located in the evaporation zone and $\mathrm{T} 1$ at the reboiler exit all show response which is typically at minimum at maximum flow rate. This may be the effect of subcooled liquid refilling. 


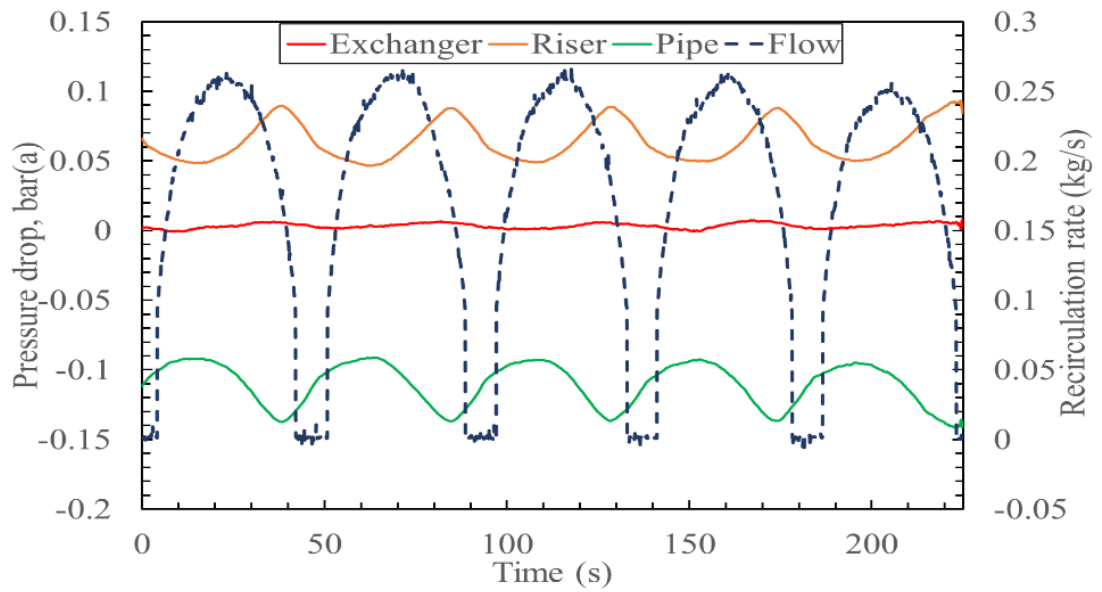

(a) Pressure drop during instability

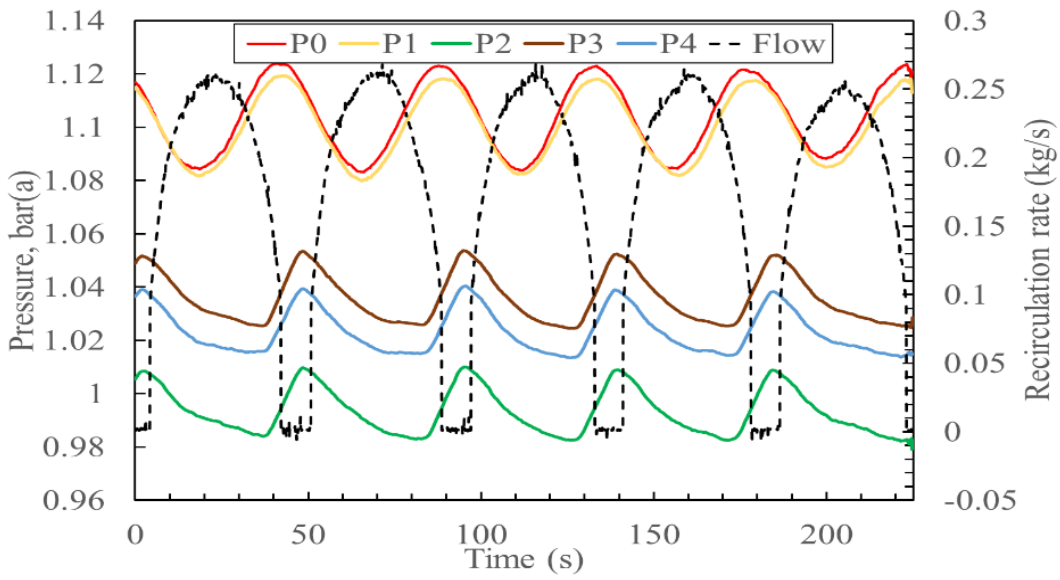

(b) Pressures in the system during instability

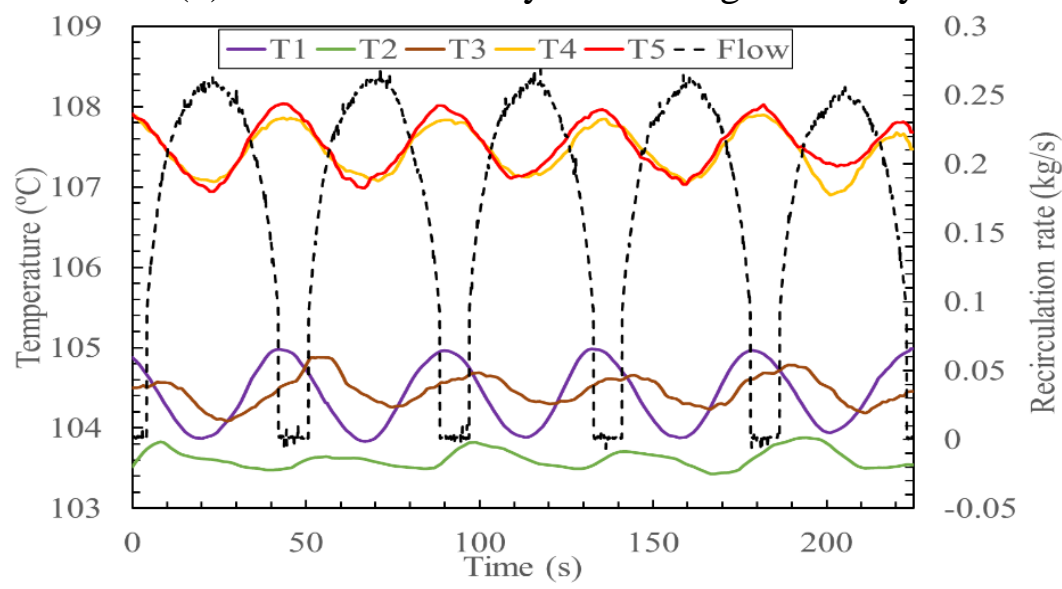

(c) Exchanger temperatures response to cyclic flow

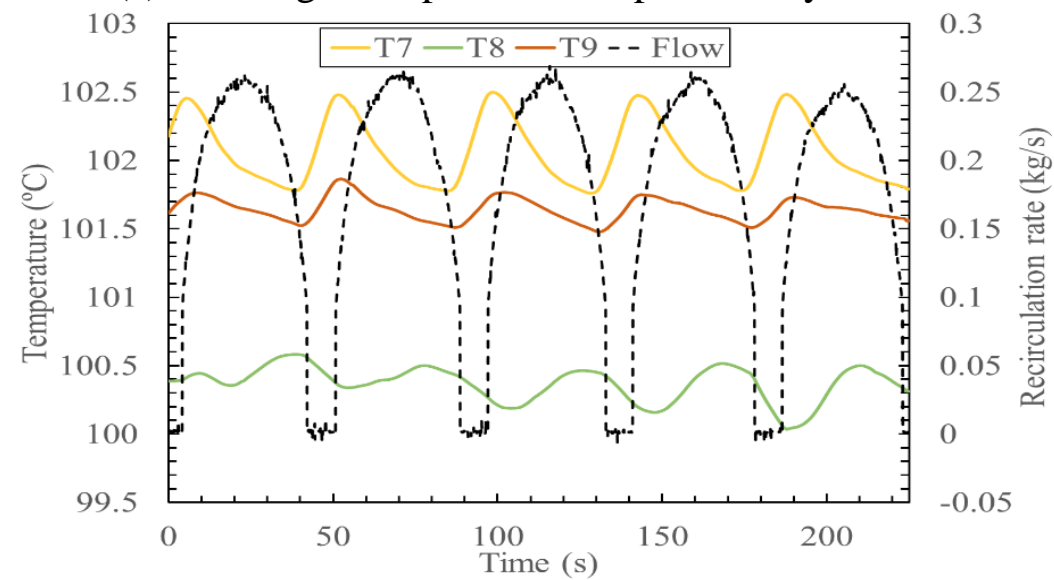

(d) Riser and pipe temperature response to cyclic flow

Figure 13: Instability observed at $14 \mathrm{~kW} / \mathrm{m}^{2}, \mathrm{~h}_{\mathrm{W}}=1.265 \mathrm{~m}, \mathrm{X}_{\mathrm{V}}=0.25$. 
The evaporation zone which is above the baffle hosts a two-phase mixture and approximately follows the vapour pressure curve. As explained earlier the maximum flow rate occurs at cessation of boiling which occurs at the start of refilling stage hence the dip in temperature values. However, temperatures $\mathrm{T} 2$ and $\mathrm{T} 3$ which are positioned within the heating zone intermittently receive subcooled liquid which is heated to boiling. This subcooled boiling process makes the heating zone highly susceptible to instability as shown in Figure 13(c) and the trend is similar to geysering instability cycle described by Kuncoro et al. (1995). Measured temperatures in the riser bend section T7, subcooled recirculation pipe T8 and vapour exit sump T9 are illustrated in Figure 13(d). They all show the trend of the geysering instability similar to that described for T2 and T3 above. This makes the reboiler, riser and sump the most coupled. It could therefore be said that the instability effect is transferred to other parts of the flow loop via the feedback mechanism ensuring continuity and hence the cyclic nature.

\section{Flow pattern characteristics}

The flow patterns observed in the present equipment has been plotted on the map as illustrated in Figure 14 which shows the majority of the flow conditions are churn or churn-annular flows though bubbly and slug flows are also observed. Flow pattern affects flow rate since different flow patterns exhibit different velocities, qualities and hold up. Hence flow pattern could be used as an indicator of the stability of the system. The flow pattern detected during the experiments is fundamentally churn especially when the heat flux is moderate and slug flow is observed when the heat flux is lowest. Churn flow and transition between churn and slug flows are detected during geysering instability. This may be due to variations in quality and flow rate. Churn-annular flow is observed at very high heat flux and flow rate where the quality is high. Low heat flux and low quality are hence linked with instability. These were cross-checked with visual observations and video recordings, stills from video are shown in Figure 15. 


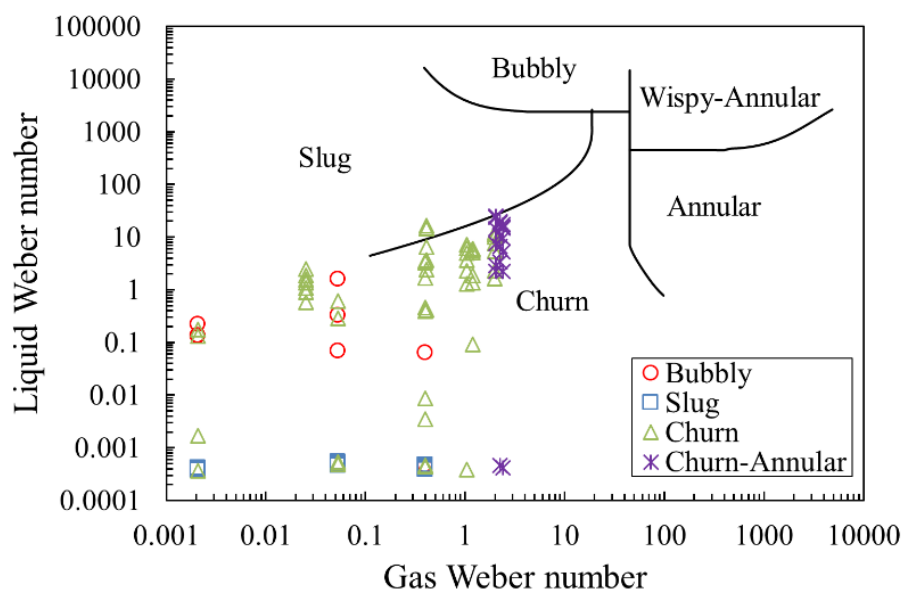

Figure 14: Two-phase flow map in the riser plotted according to Hewitt and Roberts (1969)
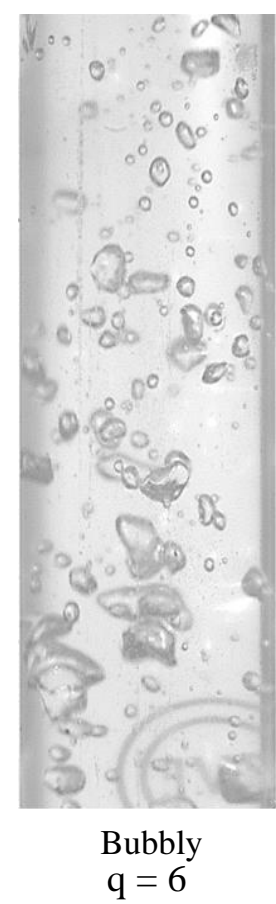

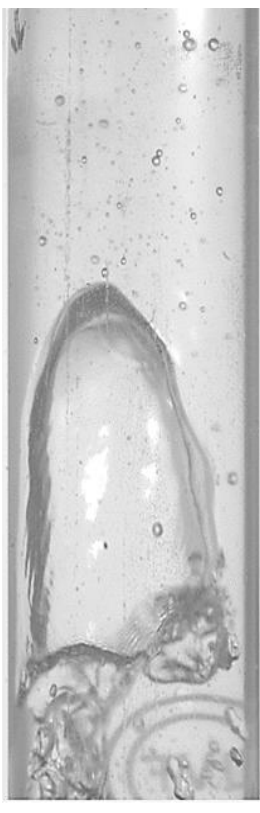

Slug

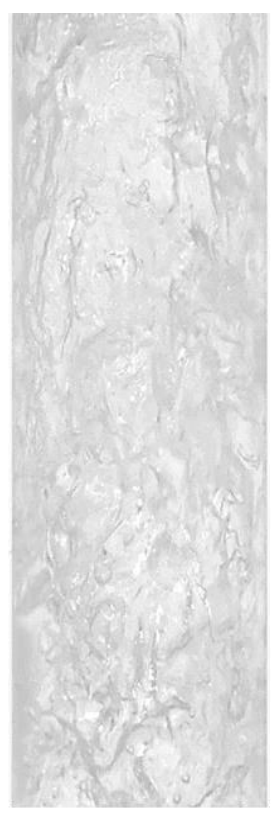

Churn

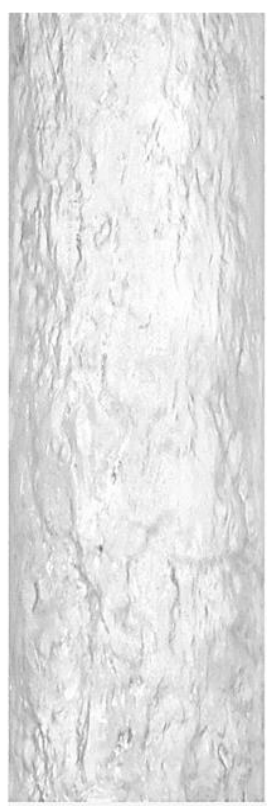

Churn-Annular $20 \mathrm{~kW} / \mathrm{m}^{2}$

Figure 15: Flow patterns observed in the riser at various heat fluxes

\section{Conclusions}

From this study of instability in a horizontal thermosyphon reboiler loop at atmospheric pressure, the following conclusions are made:

- System instability can most easily be examined by fluctuations in process fluid flow rate. Pressure and temperature also show characteristic fluctuation under instability. Geysering detected in the riser of a horizontal thermosyphon reboiler loop is an intermittent subcooled boiling condition initiated in the reboiler. It is characterized by periodical expulsions of the boiling liquid and its vapour from the riser to the sump. Geysering instability is also observed to have a connection with churn flow. Churn flow and transitions between churn and slug flows 
are detected during geysering instability which is due to variations in vapour quality and velocity. The characteristic oscillations of flow rate, pressure, and temperature under instability confirm the instability detected in the loop exhibit similar features of geysering compared with that reported for columns with closed bottom end, though the mechanism is slightly different.

- Heat flux is the most significant parameter influencing stability. Above $20 \mathrm{~kW} / \mathrm{m}^{2}$ the system is stable, between $11-20 \mathrm{~kW} / \mathrm{m}^{2}$ there are varying degrees of sustained oscillations and below 11 $\mathrm{kW} / \mathrm{m}^{2}$ the flow is low or there is no recirculation. So the system tends to stability with increasing heat flux. Three stability modes observed have been used to derive a stability map in Figure 12.

- The nonlinear recycle valve used as a means of flow restriction stabilises the system. The heat flux necessary to stabilise the system is lower at high flow restriction. Static head has some effect on stability at moderate steam pressures, but this is generally less significant.

\section{Nomenclature}
A Area
$\mathrm{C}_{\mathrm{P}} \quad$ Specific heat
h Height
$\dot{m} \quad$ Mass flow rate
P Pressure
Q Heat duty
T Temperature
U Overall heat transfer coefficient
X Opening/position

Subscripts

G Gas/vapour

L $\quad$ Liquid

$S \quad$ Steam 


$\begin{array}{ll}\text { Sat } & \text { Saturated state } \\ V & \text { Valve } \\ W & \text { Weir } \\ \text { Greek } & \\ \delta \mathrm{T}_{\text {super }} & \text { Super heat } \\ \delta \mathrm{T}_{\text {sub }} & \text { Sub-cooling } \\ \lambda & \text { Latent heat of vaporization } \\ \Delta \mathrm{T} & \text { Mean temperature difference }\end{array}$

\section{References}

Alane A and Heggs PJ. (2011) Experimental study of complex two-phase instabilities during the start-up of a vertical thermosyphon reboiler operating under vacuum. Chemical Engineering Research and Design 89: 2012-2023.

Aritomi M, Chiang JH and Mori M. (1993) Geysering in parallel boiling channels. Nuclear Engineering and Design 141: 111-121.

Azzopardi BJ and De Leon E. (2008) Instabilities in a Horizontal Thermosyphon Reboiler. HEAT 2008, Fifth International Conference on Transport Phenomena In Multiphase Systems. Bialystok, Poland.

Bergles AE. (1976) Review of instabilities in two-phase systems. NATO Advanced Study Institute on Two-phase Flow and Heat Transfer. Instanbul, Turkey.

Boure A, Bergles A and Long L. (1973) Review of Two-Phase Flow Instability. Nuclear Engineering and Design 25: 165-192.

Cheng L and Mewes D. (2006) Review of two-phase flow and flow boiling of mixtures in small and mini channels. International Journal of Multiphase Flow 32: 183-207.

Chexal VK and Bergles AE. (1972) Two-Phase Instabilities in a Low Pressure Natural Circulation Loop. AIChE Symposium Series 69, No 131: 37-45.

Dhir VK. (1998) Boiling Heat Transfer. Annual Review of Fluid Mechanics 30: 365-401.

Duffey RB and Rohatgi US. (1996) Physical interpretation of geysering phenomena and periodic boiling instability at low flows. In: Rao AS, Duffey RB and Elias D (eds) Pt A ed. New Orleans, LA, USA: ASME, 207-216.

Durga Prasad GV, Pandey M and Kalra MS. (2007) Review of research on flow instabilities in natural circulation boiling systems. Progress in Nuclear Energy 49: 429-451.

Emami MRS, Noie SH, Khoshnoodi M, et al. (2009) Investigation of Geyser Boiling Phenomenon in a Two-Phase Closed Thermosyphon. Heat Transfer Engineering 30: 408-415. 
Griffith P. (1962) Geysering in liquid-filled lines. ASME-AIChE Heat Transfer Conference. Houston, Tx.

Hewitt GF and Roberts DN. (1969) STUDIES OF TWO-PHASE FLOW PATTERNS BY SIMULTANEOUS X-RAY AND FLASH PHOTOGRAPHY. Other Information: UNCL. Orig. Receipt Date: 31-DEC-69. Medium: X; Size: Pages: 28.

Hewitt GF, Shires GL and Bott TR. (1994) Process Heat transfer: CRC Press, Inc., Boca Raton, Florida, USA.

Hills JH, Jones WE and Ibrahim AK. (1997) The Behaviour of a Pilot-Scale Horizontal Thermosyphon Reboiler. Chemical Engineering Research and Design 75: 652-656.

Ishii M. (1976) Study on Flow Instabilities in Two-Phase Flow Mixtures. Report ANL-76-23, Argonne National Laboratory.

Jiang SY, Wu XX and Zhang YJ. (2000) Experimental Study of Two-Phase Flow Oscillation in Natural Circulation. Nuclear Science and Engineering 135: 177-189.

Jiang SY, Yao MS, Bo JH, et al. (1995) Experimental simulation study on start-up of the 5 MW nuclear heating reactor. Nuclear Engineering and Design 158: 111-123.

Kakac S and Bon B. (2008) A Review of two-phase flow dynamic instabilities in tube boiling systems. International Journal of Heat and Mass Transfer 51: 399-433.

Khazaee I, Hosseini R and Noie SH. (2010) Experimental investigation of effective parameters and correlation of geyser boiling in a two-phase closed thermosyphon. Applied Thermal Engineering 30: 406-412.

Kim JM and Lee SY. (2000) Experimental observation of flow instability in a semi-closed two-phase natural circulation loop. Nuclear Engineering and Design 196: 359-367.

Kuncoro H, Rao YF and Fukuda K. (1995) An experimental study on the mechanism of geysering in a closed two-phase thermosyphon. International Journal of Multiphase Flow 21: 1243-1252.

Masuhara Y, Ustuno H, Bessho Y, et al. (1993) Research on geysering phenomena in the natural circulation BWR. San Francisco, CA, USA: Publ by ASME, 135-141.

Ozawa M, Nakanishi S, Ishigai S, et al. (1979) Flow Instabilities in Boiling Channels: Part 2 Geysering. Bulletin of The Japan Society of Mechanical Engineers 22: 1119 - 1126.

Rao YF, Fukuda K and Koga T. (1997) Experimental and numerical study of two-phase flow instabilities in natural-circulation boiling channels. In: Anon (ed). Nice, Fr: ASME, 73.

Rouhani SZ and Sohal MS. (1983) Two-phase flow patterns: A review of research results. Progress in Nuclear Energy 11: 219-259.

Saisorn S and Wongwises S. (2008) A review of two-phase gas-liquid adiabatic flow characteristics in micro-channels. Renewable and Sustainable Energy Reviews 12: 824-838.

Yadigaroglu G. (1981) Two-phase flow instabilities and propagation phenomena. In: Delhaye J. M., Goit M., Reithmuller M. L. (Eds), Thermohydraulics of Two-phase Systems for Industrial 
Design and Nuclear Engineering. 